\title{
Suppression of adjuvant-induced arthritis in the rat by gold sodium thiomalate
}

\author{
D. T. WALZ, M. J. DI MARTINO, AND A. MISHER \\ Smith Kline and French Laboratories, Philadelphia, Pennsylvania, U.S.A.
}

Gold salts have been used in the treatment of rheumatoid arthritis for nearly 40 years. Their effectiveness, while not consistent, has been well established (Freyberg, 1966) and their use continues. Recently, conflicting results concerning the effectiveness of gold salts on adjuvant arthritis in rats have been reported (Newbould, 1963; Jessop and Currey, 1968). Adjuvant arthritis, a crippling deformity resulting from diffuse connective tissue involvement, is considered by some authorities to be the best availat le experimental model of rheumatoid arthritis because of its strong clinical and pathological similarities to the human disease (Pearson, 1963), and because it can be effectively treated with most antiarthritic drugs it is widely used to evaluate potential therapeutic agents. By employing highly inbred (Lewis) rats as our experimental animals and utilizing a volume-displacement apparatus to measure the arthritic lesions objectively, we have obtained an arthritic model that is highly sensitive in detecting anti-arthritic activity.

In light of conflicting reports in the literature, we have re-evaluated the effectiveness of gold salts in adjuvant arthritis in rats under our test conditions.

\section{Material and methods}

\section{ADJUVANT ARTHRITIS}

Adjuvant was prepared by homogenizing desiccated Mycobacterium butyricum (Difco Laboratories, Detroit, Mich.) in white paraffin oil (NF) to give a suspension of $7.5 \mathrm{mg}$. $M$. butyricum $/ \mathrm{ml}$. Adjuvant arthritis was produced by a single intradermal injection of $0.1 \mathrm{ml}$. of adjuvant, on Day 0, into a footpad of the left hindpaw of male Lewis inbred rats (Microbiological Associates, Maryland) weighing between 138 and $195 \mathrm{~g}$. The rats were anaesthetized with ether inhalation before and during the adjuvant injection.

The injected hindlegs became inflamed (increased leg volume) and reached their greatest size within 3 to 5 days (primary lesion). Adjuvant arthritis (secondary lesions) occurred after a delay of approximately 10 days and was characterized by inflammation of the non-injected sites (right hindleg, forepaws, ears, nose, and tail) and further increases in the volume of the injected hindleg.

\section{HINDLEG VOLUME}

This was determined by a modified method of Van Arman, Begany, Miller, and Pless (1965). On the day of assay ( 3 to 4 hours after drug administration), the hindlegs were immersed to the anatomical hairline into a mercury reservoir. The mercury column was connected to a Statham pressure transducer (Model P23BB, 0-5 cm. Hg.). The output from the transducer was led through an amplifier to a Hewlett-Packard digital voltmeter (Model HP-3440A), and a high gain/auto range unit (Model 3443A), and finally to a digital recorder (Model J74562A). The digital recordings were calibrated, and a linear relationship between $M V$ and $M L$ was obtained by placing cylinders of known volumes into the mercury reservoir.

\section{ARTHRITIC SCORE}

The severity of secondary lesions in the uninjected hindleg was graded 0 to 4, depending upon the area and magnitude of involvement.

\section{DRUG ADMINISTRATION}

Gold sodium thiomalate (Myocrysine (\$) was prepared at various concentrations in 0.5 per cent. benzyl alcohol and injected intramuscularly (right thigh) in a volume of $0.5 \mathrm{ml} . / \mathrm{kg}$. The drug was administered once daily (exclusive of weekend days indicated in the text) starting either on Day 0 or one week before adjuvant injection and continuing until the termination of the experiment (Day 16). Control animals were treated in an identical manner using $\mathbf{0 . 5}$ per cent. benzyl alcohol for the intramuscular injections. The benzyl alcohol solution was prepared with either 0.9 per cent. saline or water for injection.

The level of significant difference between hindleg volumes, arthritic score, and body weight of drug-treated and control groups was determined by the Student's ' $t$ ' test.

SERUM GOLD LEVEL

Blood samples were obtained after the decapitation of the adjuvant arthritic rats. $0.5 \mathrm{ml}$. aliquot of serum was diluted to $3.0 \mathrm{ml}$. with distilled water and absorption measured in a Perkin-Elmer Model 303 atomic absorption spectrophotometer (wavelength $243 \cdot 3 \mathrm{~m} \mu$ slit 4 , 
lamp source 20 m.a., acetylene-air mixture and single-slot burner head) using a recorder read-out attachment and chart recorder. Peak height on the chart was converted to percentage absorption and gold levels calculated by linear regression using standard curves of aqueous aurothioglucose.

\section{Results}

\section{INITIAL EXPERIMENTS}

The data in Table I show the effects produced by 5 and $10 \mathrm{mg} . / \mathrm{kg}$. gold sodium thiomalate on the primary and secondary lesions of adjuvant arthritis in three independent experiments. Gold sodium thiomalate administered at a dose of $10 \mathrm{mg} . / \mathrm{kg}$. produced a slight but inconsistent suppression of the primary lesion (injected leg-Day 3 ). The effects of gold sodium thiomalate on the secondary lesions, however, were more consistent. On Day 16, the injected leg volumes were significantly decreased at the 10 and $5 \mathrm{mg} . / \mathrm{kg}$. doses; whereas the $10 \mathrm{mg} . / \mathrm{kg}$. dose also significantly suppressed the development of secondary lesion in the uninjected leg. Pretreating the rats with gold sodium thiomalate one week before adjuvant injection did not appear markedly to alter the results, with the exception of producing significant suppression of the injected leg volume by Day 10 .

\section{DOSE RANGE STUDY}

The effects of gold sodium thiomalate at doses of $40,20,10$, and $5 \mathrm{mg} . / \mathrm{kg}$. on the primary lesion, secondary lesions, and serum gold levels in adjuvant arthritic rats are illustrated by graphs in Figs 1, 2, and 3. Suppression of the primary lesion produced by gold sodium thiomalate, although slight, appears to be dose-related (Fig. 1).

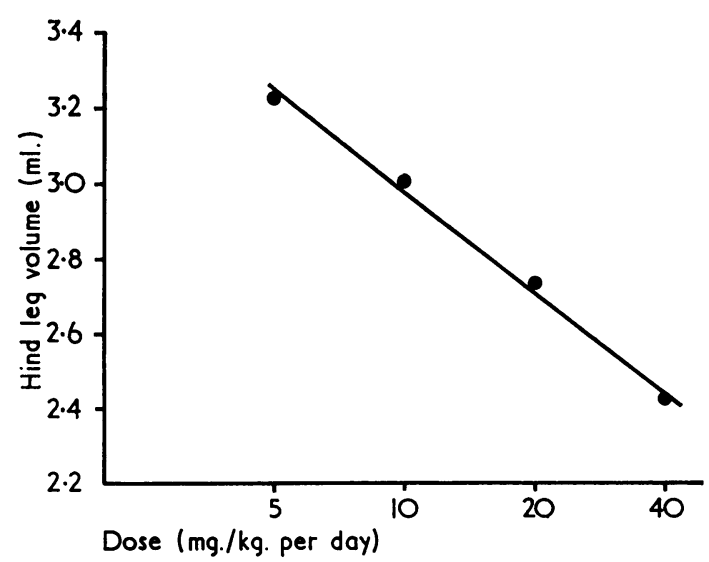

FIG. 1 Effect of various doses of gold sodium thiomalate on the primary lesion (injected hindleg volume-Day 3) of adjuvant arthritis. Mean of six rats per dose level. Vehicle control hindleg volume (mean $\perp$ S.E.) $3.02 \pm 0.07 \mathrm{ml}$.
Fig. 2 shows the dose-related suppression of the secondary lesions produced by gold sodium thiomalate. All doses of gold sodium thiomalate produced statistically significant suppression of the injected hindleg volume on Day 16 , whereas only the 20 $\mathrm{mg} . \mathrm{kg}$. dose produced a significant effect on the uninjected hindleg volume in this experiment. The relationship between daily doses of gold sodium thiomalate and gold levels in serum (collected on Day 17) is illustrated in Fig. 3. There was a significant negative correlation $(P \leqslant 0.05)$ between serum gold levels and the severity of the secondary lesion in the uninjected leg volume on Day 16.

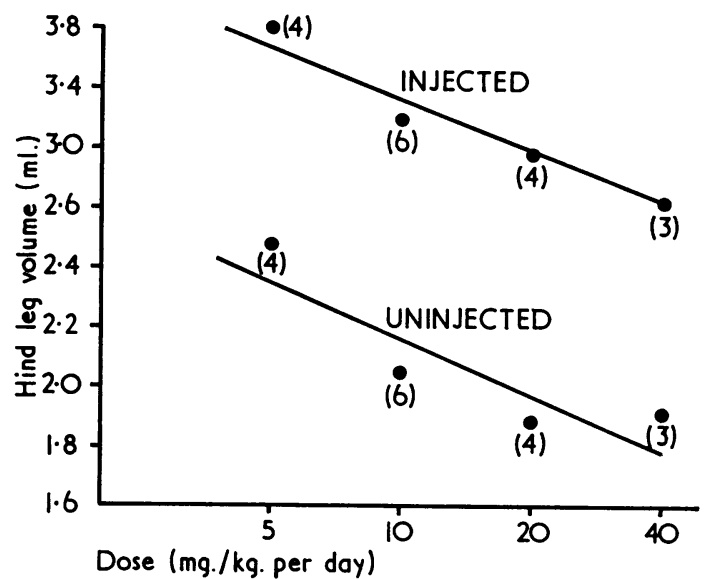

FIG. 2 Effect of various doses of gold sodium thiomalate on the secondary lesions (hindleg volumes-Day 16) of adjuvant arthritis. Mean of (3). (4), or (6) rats per dose level.

Vehicle control hindleg volume (mean $\perp$ S.E.) $4 \cdot 30 \pm$ $0 \cdot 11 \mathrm{ml}$. (injected leg) and $2 \cdot 57 \pm 0 \cdot 23 \mathrm{ml}$. (uninjected leg).

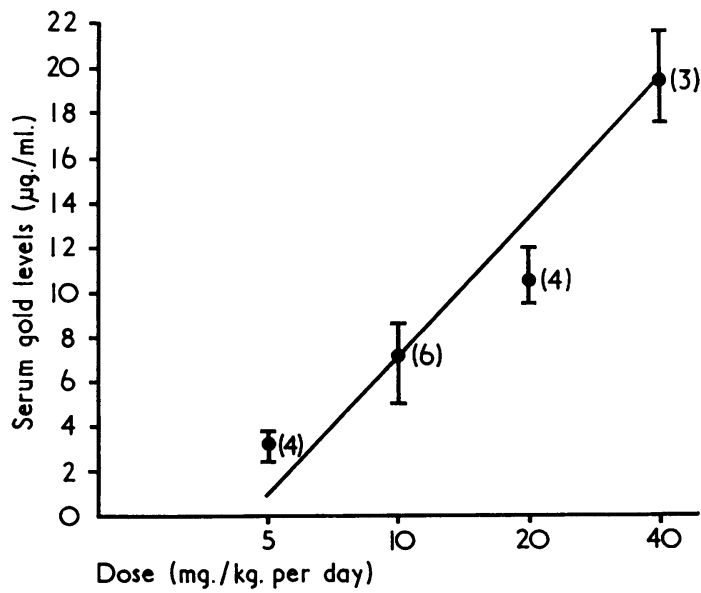

FIG. 3 Serum gold levels after administration of various doses of gold sodium thiomalate to adjuvant arthritic rats (serum obtained on Day 17). Mean and range of (3), (4), or (6) rats per dose level. 


\section{Discussion}

The results of these experiments show that gold sodium thiomalate injected into the rat inhibits both the primary and secondary lesion of induced adjuvant arthritis. It could be argued that the decreases in leg volumes are a reflection of decreases in body weight. That this is not the case is shown in Tables I and II. In these studies body weights of drugtreated rats were not significantly less than body weights of vehicle-treated rats. Pretreatment of the rat with gold sodium thiomalate one week before adjuvant injection produces essentially the same effects as those seen when gold sodium thiomalate therapy was initiated on the same day as the induction of adjuvant arthritis. These results are in agreement with the observations of Newbould (1963) on the effectiveness of gold sodium thiomalate in adjuvant-induced arthritis and also strengthen and extend his observations by showing that there is a dose-response relationship in suppressing adjuvant arthritis and elevating serum gold levels. These results are not, however, in agreement with reported
Table II Comparison of body weights in dose range study

\begin{tabular}{|c|c|c|c|}
\hline \multirow[t]{2}{*}{ Drug } & \multirow{2}{*}{$\begin{array}{l}\text { Dose } \\
\text { (mg./kg./ } \\
\text { day) }\end{array}$} & \multicolumn{2}{|c|}{$\begin{array}{l}\text { Body weight } \\
(\text { g. })(\text { mean } \pm S . E .)\end{array}$} \\
\hline & & Day 3 & Day 16 \\
\hline \multirow{4}{*}{$\begin{array}{l}\text { Gold sodium } \\
\text { thiomalate }\end{array}$} & 40 & $157 \pm 6$ & $197^{*} \pm 8$ \\
\hline & 20 & $162 \pm 5$ & $196^{*} \pm 4$ \\
\hline & 10 & $163 \pm 3$ & $177 \pm 4$ \\
\hline & 5 & $168 \pm 6$ & $179 \pm 6$ \\
\hline Control vehicle & - & $167 \pm 2$ & $177 \pm 3$ \\
\hline
\end{tabular}

*P $\leqslant 0.05$ Significant increase from control vehicle.

observations of Jessop and Currey (1968), who could not produce an effect on adjuvant-induced arthritis in rats pretreated with gold sodium thiomalate.

Since the doses of gold sodium thiomalate used in our laboratory were similar to most of those used by

Table I Effect of gold sodium thiomalate on primary and secondary lesions (hindleg volumes) in adjuvant arthritis

\begin{tabular}{|c|c|c|c|c|c|c|c|c|c|}
\hline \multirow{3}{*}{$\begin{array}{l}\text { Days }+ \text { drug } \\
\text { administered }\end{array}$} & \multirow{3}{*}{ Drug } & \multirow{3}{*}{$\begin{array}{l}\text { Dose } \\
\text { (mg.l } \\
\text { kg. } . / \\
\text { day) }\end{array}$} & \multirow{3}{*}{$\begin{array}{l}\text { No. of } \\
\text { rats } \\
\text { per } \\
\text { group }\end{array}$} & \multirow{3}{*}{$\begin{array}{l}\text { Arthritic } \\
\text { score } \\
\text { (uninjected } \\
\text { leg) }\end{array}$} & \multirow{3}{*}{$\begin{array}{l}\begin{array}{l}\text { Body } \\
\text { weight } \\
(\mathrm{g} .)\end{array} \\
\text { Day } 16\end{array}$} & \multicolumn{4}{|c|}{ Hindleg volume ( $\mathrm{ml})}$. \\
\hline & & & & & & \multicolumn{3}{|l|}{ Injected leg } & \multirow{2}{*}{$\frac{\begin{array}{l}\text { Uninjected } \\
\text { leg }\end{array}}{\text { Day } 16}$} \\
\hline & & & & & & Day $3 \dagger$ & Day 10 & Day 16 & \\
\hline \multirow[t]{2}{*}{-7 to +16} & $\begin{array}{l}\text { Gold } \\
\text { sodium } \\
\text { thiomalate }\end{array}$ & 10 & 6 & $2 \cdot 00 \pm 0 \cdot 58$ & $179 \pm 11$ & $3 \cdot 19 \pm 0 \cdot 04$ & $\stackrel{* *}{2 \cdot 65} \pm 0 \cdot 15$ & $\stackrel{* *}{3 \cdot 76 \pm 0 \cdot 36}$ & $\begin{array}{c}* * \\
2 \cdot 50 \pm 0 \cdot 28\end{array}$ \\
\hline & $\begin{array}{l}\text { Control } \\
\text { vehicle }\end{array}$ & - & 8 & $3 \cdot 12 \pm 0 \cdot 48$ & $168 \pm 6$ & $3 \cdot 31 \pm 0 \cdot 18$ & $\overline{3 \cdot 42 \pm 0 \cdot 18}$ & $\overline{4 \cdot 48 \pm 0 \cdot 16}$ & $3 \cdot 42 \pm 0 \cdot 29$ \\
\hline \multirow[t]{3}{*}{0 to +16} & $\begin{array}{l}\text { Gold } \\
\text { sodium } \\
\text { thiomalate }\end{array}$ & 10 & 6 & $\frac{*}{1 \cdot 50 \pm 0.22}$ & $178 \pm 5$ & $3 \cdot 14 \pm 0 \cdot 10$ & $2 \cdot 80 \pm 0 \cdot 10$ & $\overline{3 \cdot 62 \pm 0 \cdot 12}$ & $\stackrel{*}{*} 42 \pm 0 \cdot 11$ \\
\hline & & 5 & 6 & $2 \cdot 67 \pm 0 \cdot 42$ & $161 \pm 3$ & $3 \cdot 23 \pm 0.09$ & $2 \cdot 90 \pm 0.09$ & $3 \cdot 93 \pm 0 \cdot 11$ & $2.86 \pm 0.07$ \\
\hline & $\begin{array}{l}\text { Control } \\
\text { vehicle }\end{array}$ & - & 6 & $2 \cdot 83 \pm 0 \cdot 31$ & $\overline{166 \pm 4}$ & $3 \cdot 28 \pm 0 \cdot 06$ & $3 \cdot 14 \pm 0 \cdot 20$ & $4 \cdot 60 \pm 0 \cdot 12$ & $3 \cdot 17 \pm 0 \cdot 23$ \\
\hline \multirow[t]{3}{*}{0 to +16} & $\begin{array}{l}\text { Gold } \\
\text { sodium } \\
\text { thiomalate }\end{array}$ & 10 & 6 & $\stackrel{*}{1 \cdot 83 \pm 0 \cdot 31}$ & $167 \pm 5$ & $\stackrel{* *}{2 \cdot 49} \pm 0 \cdot 11$ & $2 \cdot 84 \pm 0 \cdot 04$ & $\begin{array}{l}{ }^{* *} \\
3 \cdot 16 \pm 0 \cdot 19 \\
*\end{array}$ & $\stackrel{*}{2 \cdot 14 \pm 0 \cdot 15}$ \\
\hline & & 5 & 6 & $2 \cdot 33 \pm 0 \cdot 21$ & $173 \pm 3$ & $2 \cdot 88 \pm 0.06$ & $2 \cdot 87 \pm 0 \cdot 18$ & $\underline{3 \cdot 34 \pm 0 \cdot 10}$ & $2 \cdot 39 \pm 0.06$ \\
\hline & $\begin{array}{l}\text { Control } \\
\text { vehicle }\end{array}$ & - & 8 & $2 \cdot 75 \pm 0 \cdot 31$ & $160 \pm 4$ & $2 \cdot 87 \pm 0 \cdot 07$ & $3 \cdot 29 \pm 0 \cdot 34$ & $3 \cdot 97 \pm 0 \cdot 19$ & $2 \cdot 80 \pm 0 \cdot 28$ \\
\hline
\end{tabular}

All values represent mean and standard error of six to eight rats.

+ Days after adjuvant injection-exclusive of days $-3,-2,+4,+5,+11,+12$

* P $\leqq 0.05$ Significant decrease from control vehicle. 
Jessop and Currey (1968), the divergent results may be due to a difference in experimental protocol. Some of the differences between our study and Jessop and Currey's work were strain of rat, adjuvant material, dosing regimen, and methods of evaluating the arthritic syndrome. It is known that both severity and response to therapy of the adjuvant-induced arthritis are affected by the strain of rat used (Swingle, Jaques, and Kvam, 1969; Pelczarska, 1969).

The fact that adjuvant-induced arthritis in rats is suppressed by steroidal and non-steroidal antiarthritic agents (Winter and Nuss, 1966; Graeme, Fabry, and Sigg, 1966), immunosuppressive drugs
(Graeme, Fabry, and Sigg, 1966), and chrysotherapy tends to confirm the utility of this disease model.

\section{Summary}

Parenteral gold, which has been shown to be effective in treating rheumatoid arthritis, was found to be effective in suppressing adjuvant-induced arthritis in the rat. Gold sodium thiomalate in a dose-related manner significantly suppressed both the primary and secondary lesions and raised the serum gold levels. The effectiveness of chrysotherapy in this experiment further supports the belief that the adjuvant-induced arthritic rat is a useful model for testing antiarthritic agents.

\section{References}

FreYberg, R. H. (1966) 'Gold Therapy for Rheumatoid Arthritis', in 'Arthritis and Allied Conditions', 7th ed., ed. J. L. Hollander, p. 311, Lea and Febiger, Philadelphia.

Graeme, M. L., Fabry, E., AND Sigg, E. B. (1956) J. Pharm. exp. Ther., 153, 373 (Mycobacterial adjuvant periarthritis in rodents and its modification by anti-in la nmatory agents).

Jessop, J. D., AND CURReY, H. L. F. (1968) Ann. rheim. Dis., 27, 577 (Influence of gold salts on adjuvant arthritis in the rat).

Newbould, B. B. (1953) Brit. J. Phar., 21, 127 (Chemotherapy of arthritis induced in rats by mycobacterial adjuvant).

PeARSON, C. M. (1963) J. chron. Dis., 16, 863 (Experimental joint disease. Observations on adjuvant-induced arthritis).

Pelczarska, A. (1969) J. Pharm. Pharmacol., 21, 692 (Treatment of adjuvant arthritis in rats with the histidine decarboxylase inhibitor hypostamine).

Swingle, K. F., JaQues, L. W., AND Kvam, D. C. (1969) Proc. Soc. exp. Biol. (N.Y.), 132, 608 (Differences in the severity of adjuvant arthritis in four strains of rats).

Van Arman, C. G., Begany, A. J., Miller, L. M., and Pless, H. H. (1965) J. Pharmacol. exp. Ther., 150, 328 (Some details of the inflammations caused by yeast and carrageenin).

Winter, C. A., AND Nuss, G. W. (1966) Arthr. and Rheum., 9, 394 (Treatment of adjuvant arthritis in rats with anti-inflammatory drugs). 